\title{
Satisfaction of Tunisian Healthcare Staff Towards Preparedness of Covid-19
}

\author{
Salhi Rihab ${ }^{1} \quad$ Ghalgeoui Abdelbasset ${ }^{2}$ \\ 1.PhD Student in health science pedagogy, Emergency and resuscitation nurse, Paramedical health care Teacher \\ 2.Major nurse in Charles Nicolle Hospital in Tunis
}

\begin{abstract}
Introduction: Since December 2019, china, where the first cases appeared, has declared that it is fighting a new generation of Betacoronavirus from the corona family. She was shocked at the speed of transmission of this virus (Zhang, 2020; Li, 2020; Zhu et al, 2020; Misra, 2020). The start of this pandemic was sudden for everyone but all health systems must be well prepared to fight this health emergency (Zhang, 2020). Tunisia recorded its first case in 02 March 2020, three months after the onset of infection in China. According to INEAS (2020), it important to prevent the transmission of this virus by protecting hospitals and health care workers. To discover what happened in the practice side, this survey will conducted.

Aim: To describe the satisfaction of health professionals with the strategy adopted by the Ministry of Health and the new measures taken by hospitals, as well as the availability of protective equipment and the dissemination of information.

Methodology: This survey is a quantitative descriptive cross-sectional study which will study satisfaction among healthcare staff. It was carried out in multiple hospitals in Tunisia in 21 days from March 2020 until April 2020. Finally, 454 healthcare professionals agreed to participate in our study $(n=454)$. An auto-administrative questionnaire was distributed to the participants.

Results: Most of the respondents are young people, which explains why $83,3 \%$ of them have professional experience $<10$ years. More than 50\% were not involved in decision-making either in the hospital or in the department in which he works. More than $70 \%$ did not participate either in training on hygiene measures or on triage of patients or on the white plan and the precision of the role of each. More than $60 \%$ of the participants were not satisfied with the availability of protection material except for the disposable gutters and for the liquid soap.

Conclusion: Despite the fact that Tunisia has experienced the pandemic of SARS-Cov-2 late in comparison to other countries, the health professionals were not satisfied with the procedures and preconceptions put in place.

Keywords: SARS-Cov-2, professional health care, satisfaction, pandemic
\end{abstract}

DOI: $10.7176 / \mathrm{JHMN} / 76-09$

Publication date:June 30th 2020

\section{Introduction}

Humanity and the world has known several pathologies which have been declared as a universal emergency by the world health organization (WHO) like H1N1 en 2009 which caused the death of 18 000, Ebola in 2013, Zika virus in 2013, SARS (Sever Acute Respiratory Syndrome) in 2002-2003, and SARS-Cov-2 that we are currently experiencing (Zhu et al, 2020; Yan et al, 2020). Since December 2019, china, where the first cases appeared, has declared that it is fighting a new generation of Betacoronavirus from the corona family. She was shocked at the speed of transmission of this virus (Zhang, 2020; Li, 2020; Zhu et al, 2020; Misra, 2020). Very quickly, this virus is found in the majority of the countries of the world with tragedy scenarios in some countries which have recorded a large number of cases and deaths like Italy and USA (Wang, 2020). This new virus called SARS-Cov-2 is transmitted by the respiratory tract and by contact with a person or an object infected by this virus (Zhang, 2020). This seventh generation of coronavirus causes signs of flu and attacks epithelial cells in the lungs (Zhu, 2020). This pandemic has created worldwide disruption by affecting several areas in the countries: economic since the citizens were forced to stay at home at home, psychological whether it be on people or especially health professionals who were in direct contact with the virus and unfortunately the world has recorded cases of deaths of healthcare professionals who have been infected by patients (Zhang, 2020; Zhu et al , 2020). The start of this pandemic was sudden for everyone but all health systems must be well prepared to fight this health emergency (Zhang, 2020).

Tunisia recorded its first case in 02 March 2020, three months after the onset of infection in China. Theoretically, the Tunisian health system must be well equipped in hospitals and normally there must be a clear strategy to succeed in the war.

In this case, l'INEAS was the first establishment who published a very important document about the protection against COVID-19. This publication was defined this new virus and his symptoms. It also clarify the different modality of giving care to hemodialysis patients, cardiac patients, pediatric patients and the health working professionals who caught SARS-Cov-2. It devoted a part to talking about protection equipment to use in many area of hospital such as operating room. Moreover, it cited the deferent steps which must be respected by 
health workers when they start to treat or transport a SARS-Cov-2 patient or corpse. Finally, it, explain who health workers can use the COVID-19s' circuit in emergency room to make the difference and protect both health workers and the other patients (INEAS; 2020).

To discover what happened in practice side, this survey will conducted. In fact, this work aims to describe the satisfaction of health professionals with the strategy adopted by the Ministry of Health and the new measures taken by hospitals, as well as the availability of protective equipment and the dissemination of information.

\section{Methodology}

This survey is a quantitative descriptive cross-sectional study which will study satisfaction among healthcare staff. It was carried out in multiple hospitals in Tunisia in 21 days from March 20, 2020 until April 10, 2020. This work targets health personnel who work in the hospitals of great Tunis. The inclusion criteria are: being a health professional working in one of the hospitals in the greater Tunis during the SARS-COV-2 pandemic period. The doctors and the administrative staff are excluded from this study. Finally, 454 healthcare professionals agreed to participate in our study $(\mathrm{n}=454)$.

\section{Questionnaire}

The questionnaires consist of two parts: The first part is made by socio-demographic and professional data. The second part, included 35 items, is made with a Likert scale. Each item is coded from 1 to 5: 1= Very satisfied, $2=$ Satisfied, $3=$ Neutral, $4=$ Dissatisfied, $5=$ Very dissatisfied.

\section{Data analyses}

The questionnaire data were entered in Statistical Package for Social Sciences (SPSS) version 22. In the descriptive part, we determined the mean and the extremes for the quantitative variables. For qualitative variables, we determined the relative percentages of each category.

\section{Ethics considerations}

Free and informed consent of the participants was obtained following the description of the study's main objective and the explanation of the participant's responsibilities.

The questionnaires are anonymous and each nurse completes only one questionnaire.

\section{Results}

Table $\mathrm{N}^{\circ} 1$ : Participants characteristics $(\mathrm{N}=454)$

\begin{tabular}{|c|c|c|c|c|}
\hline Characteristics & Cathegories & $\mathbf{n}$ & $(\%)$ & $\mathbf{M} \pm \mathbf{S D}$ \\
\hline \multirow[b]{2}{*}{ Gender } & Male & 220 & 48,5 & \multirow[b]{5}{*}{$31,37 \pm 7,37$} \\
\hline & Female & 234 & 51,5 & \\
\hline \multirow[b]{3}{*}{ Age (years) } & $\leq 35$ & 364 & 80,2 & \\
\hline & {$[36-50]$} & 78 & 17,2 & \\
\hline & $>50$ & 12 & 2,6 & \\
\hline \multirow[b]{2}{*}{ Marital status } & Unmarr & 270 & 59,5 & \\
\hline & Married & 184 & 40,5 & \\
\hline \multirow[b]{4}{*}{ Hospital } & University hospital & 200 & 44,1 & \\
\hline & Regional hospital & 86 & 18,9 & \\
\hline & Constituency hospital & 94 & 20,7 & \\
\hline & Private hospital & 74 & 16,3 & \\
\hline \multirow[b]{3}{*}{ Service } & Medical services & 318 & 70 & \\
\hline & Surgical services & 120 & 26,4 & \\
\hline & Mixed & 16 & 3,5 & \\
\hline \multirow[b]{3}{*}{ Profession } & Nurse & 312 & 68,7 & \\
\hline & Health care technician & 128 & 28,2 & \\
\hline & Auxillary (assistant) nurse & 14 & 3,1 & \\
\hline \multirow{3}{*}{$\begin{array}{l}\text { Work } \\
\text { Experience } \\
\text { (years) }\end{array}$} & $\leq 10$ & 378 & 83,3 & \multirow{3}{*}{$6,92 \pm 6,83$} \\
\hline & {$[11-20]$} & 52 & 11,5 & \\
\hline & $>20$ & 24 & 5,3 & \\
\hline
\end{tabular}

The sample has almost the same distribution by sex of the participants. However, most of the respondents are young people, which explains why $83,3 \%$ of them have professional experience $<10$ years. For the first section, which concerns communication and information, the participants showed great disappointment. In fact, more than $50 \%$ were not involved in decision-making either in the hospital or in the department in which he works. Furthermore, they did not participate in meetings to get training and information about this new virus. For health 
care professions who participated in this study, coordination with the medical profession remains poor. For the second dimension concerning continuing education, health professionals were extremely dissatisfied. In fact, more than $70 \%$ did not participate either in training on hygiene measures or on triage of patients or on the white plan and the precision of the role of each. For the third dimension, which concerns the availability of protective equipment and materials, the percentage of dissatisfaction was very higher. In fact, more than $60 \%$ of the participants were not satisfied with the availability of protection material except for the disposable gutters and for the liquid soap. The percentage was more than $80 \%$ for disposable combination. For the disinfection of service units, the surveys were not satisfied on the surface disinfection products and services sterilization did not achieve. If we are going to classify the dimensions according to their percentages, we find that the participants are rather not satisfied with the staff and the measures taken by the hospitals. They assigned the highest percentage for the dimension of personnel training to fight against this pandemic $(84.6 \%)$, then the dimension of the availability of personnel protective equipment $(82.4 \%)$.

Table N²: The percentage of satisfaction for each dimension:

\begin{tabular}{|l|l|l|l|l|l|}
\hline Variables & $\begin{array}{l}\text { Very } \\
\text { dissatisfied }\end{array}$ & Dissatisfied & Neutral & Satisfied & $\begin{array}{l}\text { Very } \\
\text { satisfied }\end{array}$ \\
\hline Communication and information & $38,9 \%$ & $34,3 \%$ & $9,7 \%$ & $13,0 \%$ & $4,1 \%$ \\
\hline Continues formation & $42,1 \%$ & $34,6 \%$ & $12,9 \%$ & $7,2 \%$ & $3,3 \%$ \\
\hline $\begin{array}{l}\text { Availability of Personnel Protective Equipment } \\
\text { (PPE) }\end{array}$ & $39,7 \%$ & $25,7 \%$ & $11,5 \%$ & $15,3 \%$ & $7,7 \%$ \\
\hline Disinfection of services & $25,3 \%$ & $28,0 \%$ & $17,6 \%$ & $23,2 \%$ & $5,9 \%$ \\
\hline
\end{tabular}

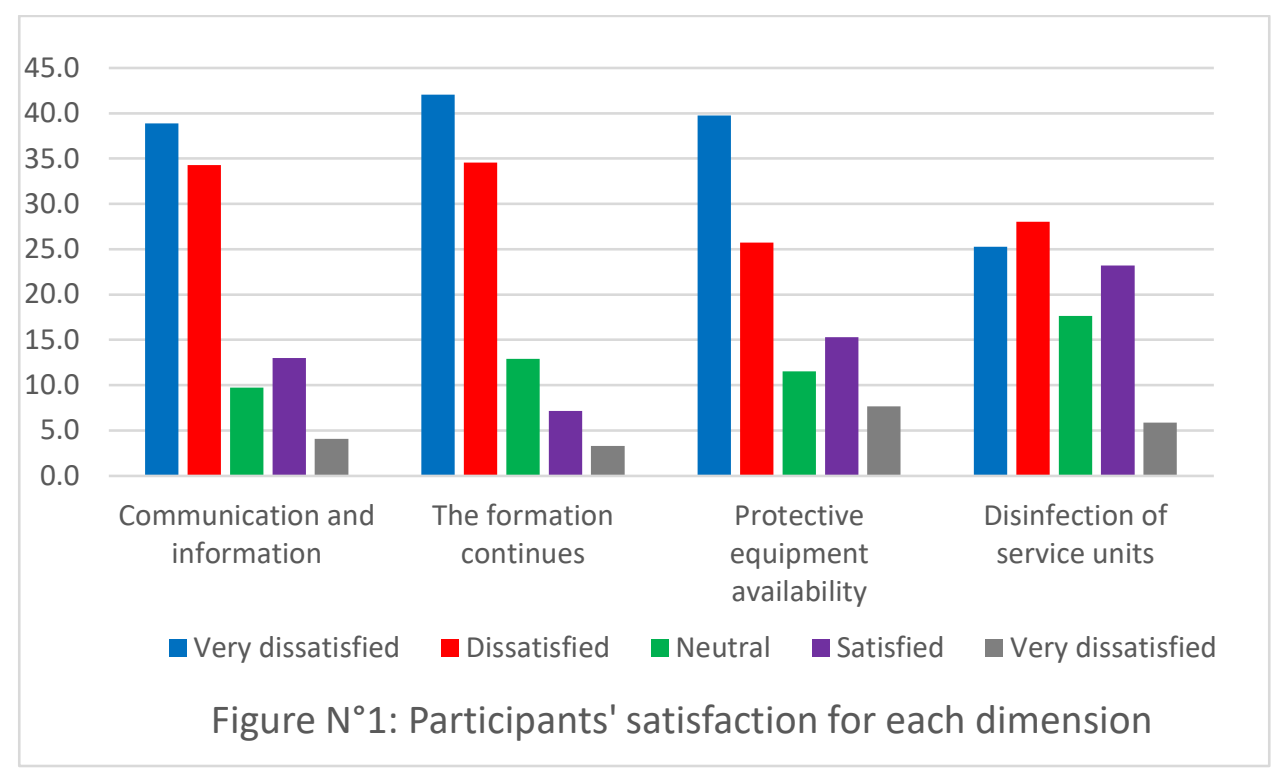

\section{Discussion}

The goal of this survey descriptive quantitative was to describe the satisfaction of health professionals with the strategy adopted by the Ministry of Health and the new measures taken by hospitals, as well as the availability of protective equipment and the dissemination of information. The results from this work were alarming and shocking. In fact, more than $70 \%$ of the participants were either dissatisfied or very dissatisfied with the measures taken by their hospitals and by the way of managing this critical health situation. In addition, the health professionals who participated in this study expressed their disappointment with the passage of information from the hierarchical superiors to the clinicians. Also, they were neither well trained about this new virus, not involved in decisionmaking even for measures which concern them. In this section, we discuss this survey dimension by dimension.

1) Communication and information and continues formation:

These were the first two dimensions that gagged very dissatisfied by professional health workers. In fact, according to the participants, hospitals don't have a clear strategy to form their health care workers about SARS-Cov-2 as a new virus and a few education sessions were necessary. Actually, 30,4\% were very dissatisfied about their participation on a meeting about SARS-Cov-2. Moreover, more than $50 \%$ are also very dissatisfied about the absence of support of their leaders and 78,4\% were also dissatisfied because their hospitals did not provide continuing education sessions neither on the modalities of protection against this new virus nor on the white plan Those finding are similar to the results of the survey of Sagar in 2015. For author nurses "leading the fight against Ebola virus disease". That's why they recommended that nurses must be implicated when decision will take by 
the decision-makers. According to this article, the important of nurses role in caring patients who have Ebola virus without stigmatization, their disponibility in any health crisis despite the dangers, and the wasted time of their lives because of this diligent profession, forces politicians to involve nurses in decision-making during this type of health crisis. This is not easy to realize in underdevelopment countries, that why authors invited nurses to "seek a place at the table" for caregivers to change their negligence on the nurses and just consider them as task exactors.

2) Availability Personnel Protective Equipment (PPE):

In this study, participants were expressed their dissatisfaction especially for FFP2 masks, glasses $(61,2 \%)$, surgical boot $(51,1 \%)$. Misra (2020) confirmed that it is very important to make available the equipment personal protective especially in hospital because doctors and professional health care are exposed to strong risqué of contamination. Author added that, it is not easy to achieve this goal because all the world need to have this type of equipment. Author added that "In China, despite high priority and dedicated funding, many healthcare workers bought protective gear with their own money or borrowed cash or donations from friends in china or other countries". Furthermore, Delgado et al (2020), in their survey found that health care professionals have a limited access to PPE during SARS-COV-2 pandemic. This similarity can be explained by the universal and ubiquitous nature of this pandemic which has paralyzed the whole world. Literature said that to win this wear against SARS-COV-2, it is important to protect health care worker because they are in front direct if the virus. It is crucial to reduce professional- patient transmission and professional-professional transmission (Crossmark; 2020).

3) Units' sterilization:

More than $40 \%$ of participants were dissatisfied about units' sterilization. They were not satisfied by machines, rooms' sterilization and also about the availability of hygiene products Hero (2020) declared that among the urgent precautions that must be taken is the protection of health professionals. It is not that Tunisia which encounters this problem.in fact, by personnel protective equipment (PPE), and sterilization of rooms, services and all departments of hospital. Author added that it is essential to do this if we want to prevent a tragedy scenario.

Kollie in 2016 with nurses and midwifes with Ebola in Liberia. Indeed, by a qualitative study, author understood how participants have lived this experience. She found that, Ebola experience was a scarred experience which changed the rhythm of their lives because they "living in fear and terror". Even their relations with patient and with themselves were modified. These changes also influenced their family lives. That why author declared that, supervisors and policy must think about those crucial elements when they declare theirs decisions.

\section{Conclusion}

Despite the fact that Tunisia has experienced the pandemic of SARS-Cov-2 late in comparison to other countries, the health professionals were not satisfied with the procedures and preconceptions put in place. The reaction of the hospitals in this study is not effective and suitable for clinicians. The results of this study invite the authorities to take measures to manage this type of situation in the future. It is important to react effectively and quickly to minimize the damage.

\section{Study's limitations:}

This survey interested just the hospitals of the capital. We don't have an idea about the other hospitals. A notational survey may be able to give us a clear vision and it can demonstrate if there are differences between the different heath structures.

The present critical situation (SARS-Cov-2) influenced the number of the participants to this study.

\section{Acknowledgement}

We would like to think all professional health care who participated of this survey.

\section{References}

- Delgado D, Wyss Quintana F, Perez G, Sosa Liprandi A, Ponte-Negretti C, Mendoza I et al. Personal Safety during the COVID-19 Pandemic: Realities and Perspectives of Healthcare Workers in Latin America. International Journal of Environmental Research and Public Health. 2020;17(8):2798.

- Hero I. Prevent loss of life by providing all NHS staff with WHO standard personal protective equipment. BMJ. 2020:m1275.

- $\quad$ Instance Nationale de l'Évaluation et de l'Accréditation en Santé /Direction Qualité des Soins et Sécurité des patients. Guide Parcours du patient suspect ou atteint par le Covid-19. Tunis : Consensus d'experts ; 2020.

- Kollie E, Winslow B, Pothier P, Gaede D. Deciding to work during the Ebola outbreak: The voices and experiences of nurses and midwives in Liberia. International Journal of Africa Nursing Sciences. 2017; 7:7581.

- $\quad$ Li W, Yang Y, Liu Z, Zhao Y, Zhang Q, Zhang L et al. Progression of Mental Health Services during the COVID-19 Outbreak in China. International Journal of Biological Sciences. 2020 ; 16(10) :1732-1738.

- Misra A. Doctors and healthcare workers at frontline of COVID 19 epidemic: Admiration, a pat on the back, 
and need for extreme caution. Diabetes \& Metabolic Syndrome: Clinical Research \& Reviews. 2020; 14(3):255-256.

- Sagar P. Nurses Leading the Fight Against Ebola Virus Disease. Journal of Transcultural Nursing. 2015 ; 26(3):322-326.

- $\quad$ The Lancet. COVID-19: protecting health-care workers. The Lancet. 2020; 395(10228):922.

- Wang Y, Di Y, Ye J, Wei W. Study on the public psychological states and its related factors during the outbreak of coronavirus disease 2019 (COVID-19) in some regions of China. Psychology, Health \& Medicine. 2020:1-10.

- Yan Y, Chen H, Chen L, Cheng B, Diao P, Dong L et al. Consensus of Chinese experts on protection of skin and mucous membrane barrier for healthcare workers fighting against coronavirus disease 2019. Dermatologic Therapy. 2020.

- Zhang, J., Wu, W., Zhao, X. and Zhang, W., 2020. Recommended psychological crisis intervention response to the 2019 novel coronavirus pneumonia outbreak in China: a model of West China Hospital. Precision Clinical Medicine, 3(1), pp.3-8.

- Zhu N, Zhang D, Wang W, Li X, Yang B, Song J et al. A Novel Coronavirus from Patients with Pneumonia in China, 2019. New England Journal of Medicine. 2020; 382(8):727-733.

- $\quad$ Zhu Z, Xu S, Wang H, Liu Z, Wu J, Li G et al. COVID-19 in Wuhan: Immediate Psychological Impact on 5062 Health Workers. 2020. 